UCRL-JC-128370

PREPRINT

\title{
Transport and Handling of National Ignition Facility Beamline Optic Modules
}

\author{
S. C. Yakuma, E. L. Grasz, A. W. Rowe, \\ G. Yourchenko, D. A. Swan, G. M. Robles
}

This paper was prepared for and presented at the SPIE International Symposium on High-Power Lasers and Applications

San Jose California

January 24-30, 1998

December 23, 1997

This is a preprint of a paper intended for publication in a journal or proceedings. Since changes may be made before publication, this preprint is made available with the understanding that it will not be cited or reproduced without the permission of the author. 


\section{DISCLAIMER}

This document was prepared as an account of work sponsored by an agency of the United States Government. Neither the United States Government nor the University of California nor any of their employees, makes any warranty, express or implied, or assumes any legal liability or responsibility for the accuracy, completeness, or usefulness of any information, apparatus, product, or process disclosed, or represents that its use would not infringe privately owned rights. Reference herein to any specific commercial product, process, or service by trade name, trademark, manufacturer, or otherwise, does not necessarily constitute or imply its endorsement, recommendation, or favoring by the United States Government or the University of California. The views and opinions of authors expressed herein do not necessarily state or reflect those of the United States Government or the University of California, and shall not be used for advertising or product endorsement purposes. 


\title{
Transport and Handling of National Ignition Facility Beamline Optic Modules
}

\author{
S. C. Yakuma, E. L. Grasz, A. W. Rowe, G. Yourchenko, D. A. Swan, and G. M. Robles \\ National Ignition Facility Operation Engineering Team \\ Lawrence Livermore National Laboratory, P.O. Box 808, L-447, Livermore, CA 94550
}

\begin{abstract}
Installing the thousands of optics that make up the laser for the National Ignition Facility (NIF) is a complex operation. This paper introduces the Optical Transport and Material Handling designs that will be used to deliver the optics. The transport and handling hardware is being designed to allow autonomous, semiautonomous, and manual operations.
\end{abstract}

\section{INTRODUCTION}

The U.S. Department of Energy (DOE) is currently planning and building the National Ignition Facility (NIF). The NIF is an advanced, high-power laser facility for Inertial Confinement Fusion (ICF) research and applications. This facility is expected to reach fusion ignition and to make significant contributions to the DOE's Defense Programs Stockpile Stewardship mission. Furthermore, important scientific and technological issues can also be examined with this facility, thus allowing informed decisions to be made on the ability of ICF to contribute to the nation's energy needs in the 21 st century and beyond.

In the NIF facility, 192 high-energy laser beams will be focused onto a small target in the center of a spherical chamber, with all their encrgy being depositcd on the target in a few billionths of a sccond. ${ }^{1}$ As the target implodes, atomic nuclei inside it will be forced together closely enough to achieve a miniature fusion reaction.

The NIF project has currently broken ground and is building the foundation of the buildings that will house the laser. There are two primary buildings: the Optics Assembly Building (OAB) and the Laser and Target Area Building (LTAB). See Figure 1. The $\mathrm{OAB}$ will provide the facilities necessary for assembling and aligning the components that make up the optical path of the laser. The LTAB will house the laser system and the spherical target chamber. These buildings will cover a total area of about three acres.

The design philosophy for the NIF is to modularize the laser optical components. Each laser component will be packaged into a line-replaceable unit (LRU), which will allow efficient, safe, and cost-effective assembly, transportation, installation, and removal. An LRU will typically comprise a mechanical housing, laser optics (lenses and mirrors), utilities, actuators, and kinematic mounts. Most LRUs will be assembled and aligned in the OAB by processing LRU subcomponents as they are needed.

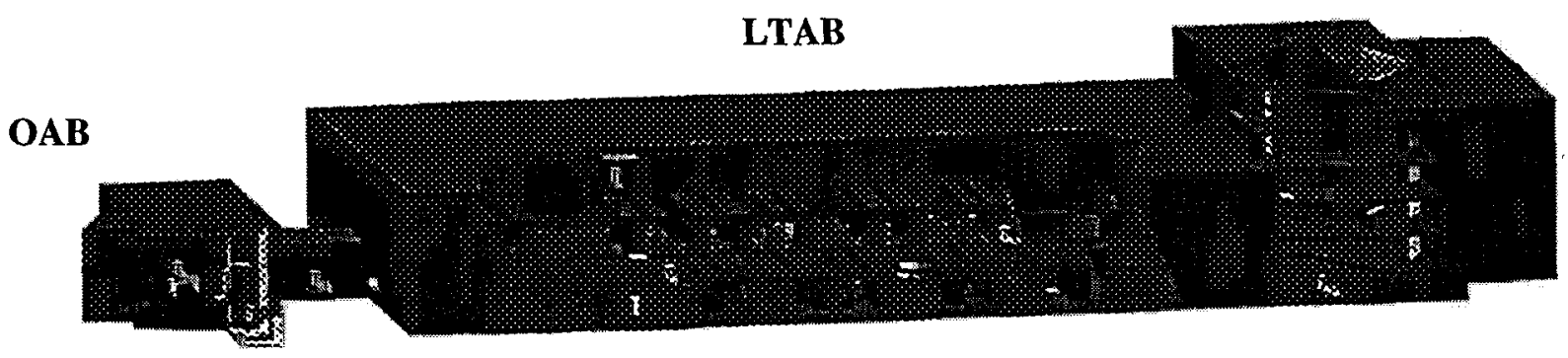

Figure 1. The main buildings for the NIF project are the Optics Assembly Building and the Laser and Target Area Building. 
The Optical Transport and Material Handling team of the NIF project has the role to develop the systems required to deliver the LRUs to the beamline. The delivery systems provide the methodology and equipment necessary for transporting and installing/removing the optical LRU assemblies to and from their installed positions and maintenance and assembly facilities.

\section{TECHNICAL APPROACH}

Five types of delivery systems are being developed for the NIF project. The five delivery systems are the Laser Bay Bottom Loading, the Laser Bay Top Loading, the Laser Bay Side Loading, the Switchyard Loading, and the Target Area Loading. See Figures 2 to 6 . The delivery systems are designed to maintain the optical LRU assemblies' specified shock, vibration, cleanliness, and environmental requirements during all operations.

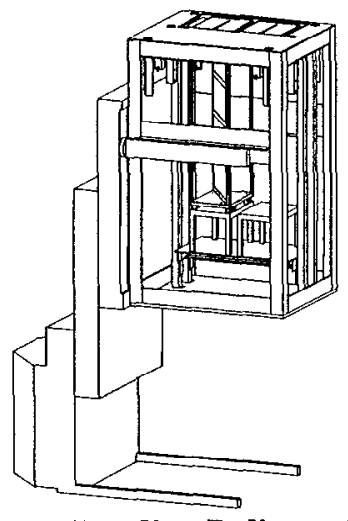

Figure 2. Bottom Loading Delivery System.

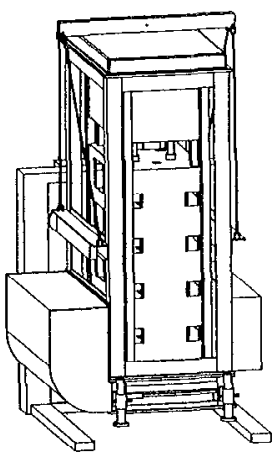

Figure 3. Top Loading Delivery System.

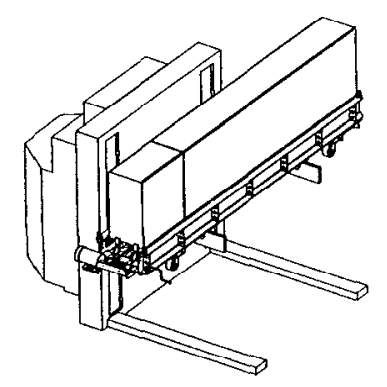

Figure 4. Side Loading Delivery System.

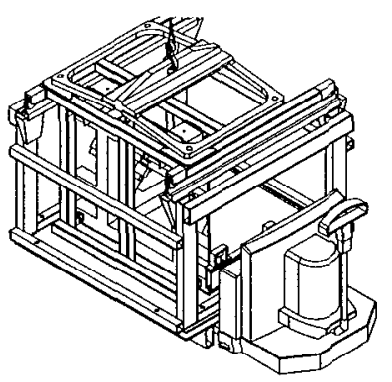

Figure 5. Switchyard Loading Delivery System.

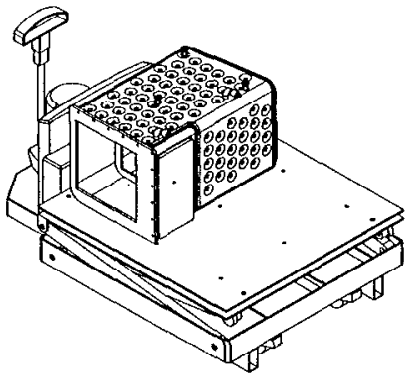

Figure 6. Target Area Delivery System.

The delivery systems are designed to transport and install 41 different types of optical LRUs. See Figure 7. There are two classes of optical LRUs. There are "bare" LRUs and "enclosed" LRUs. The bare LRUs have exposed "glass" and must be delivered in an enclosure or canister to preserve the cleanliness and environment of the optics. The enclosed LRUs are already housed inside an enclosure/box. These optics are already protected and do not require any other protection. The LRUs have various locations throughout the Laser Bays, Switchyards, and Target Area. See Figure 8.

The major design requirements specified for each of the delivery systems include:

- Preserving the cleanliness (Mil Std 1246 level 50) of the LRU optics.

- Preserving the LRU's functionality and alignment.

- Maximizing on commonality for the delivery systems for the LRUs.

- Meeting the beamline schedule with rapid installation and removal of the LRUs. 


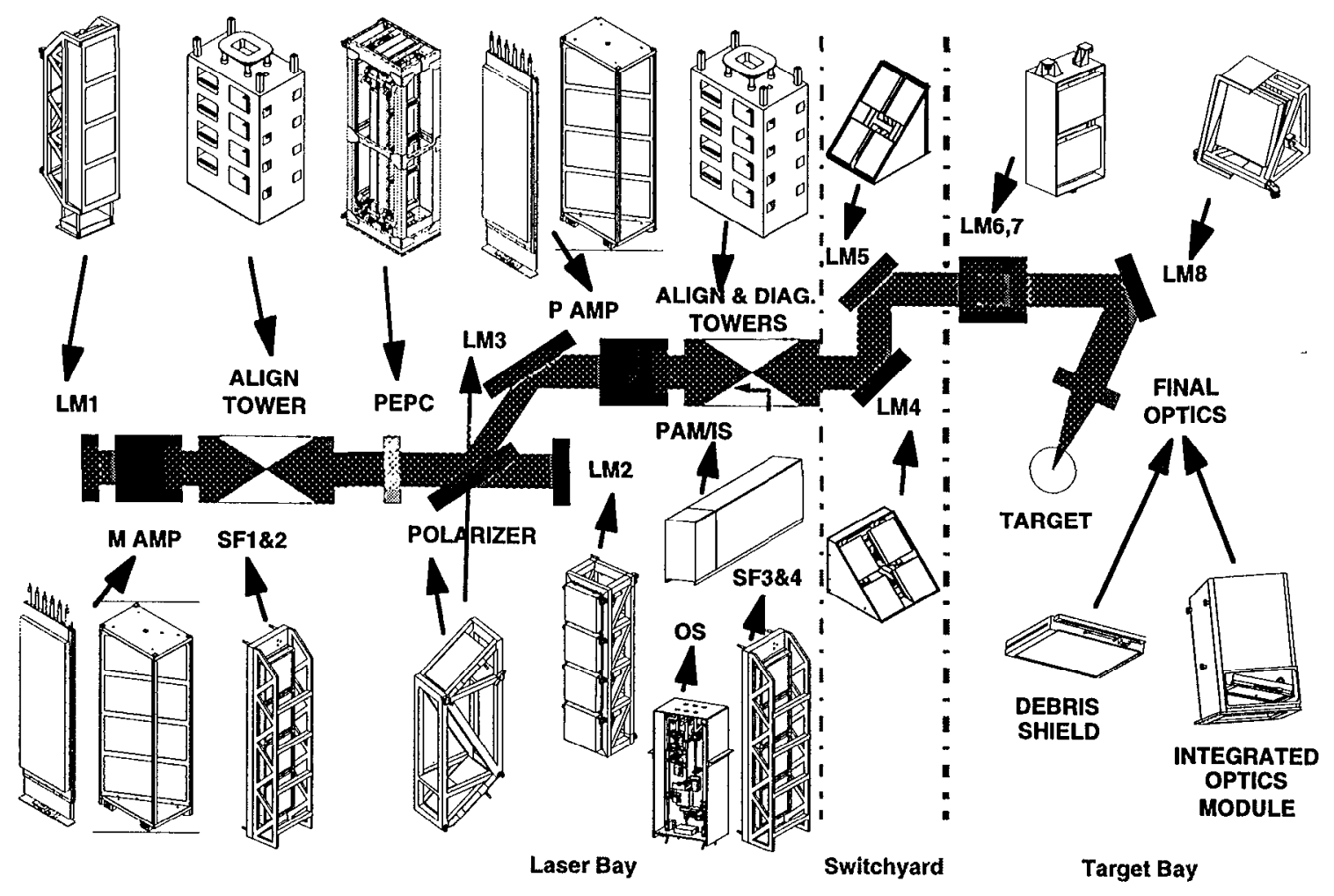

Figure 7. The NIF LRUs come in a variety of sizes and configurations.

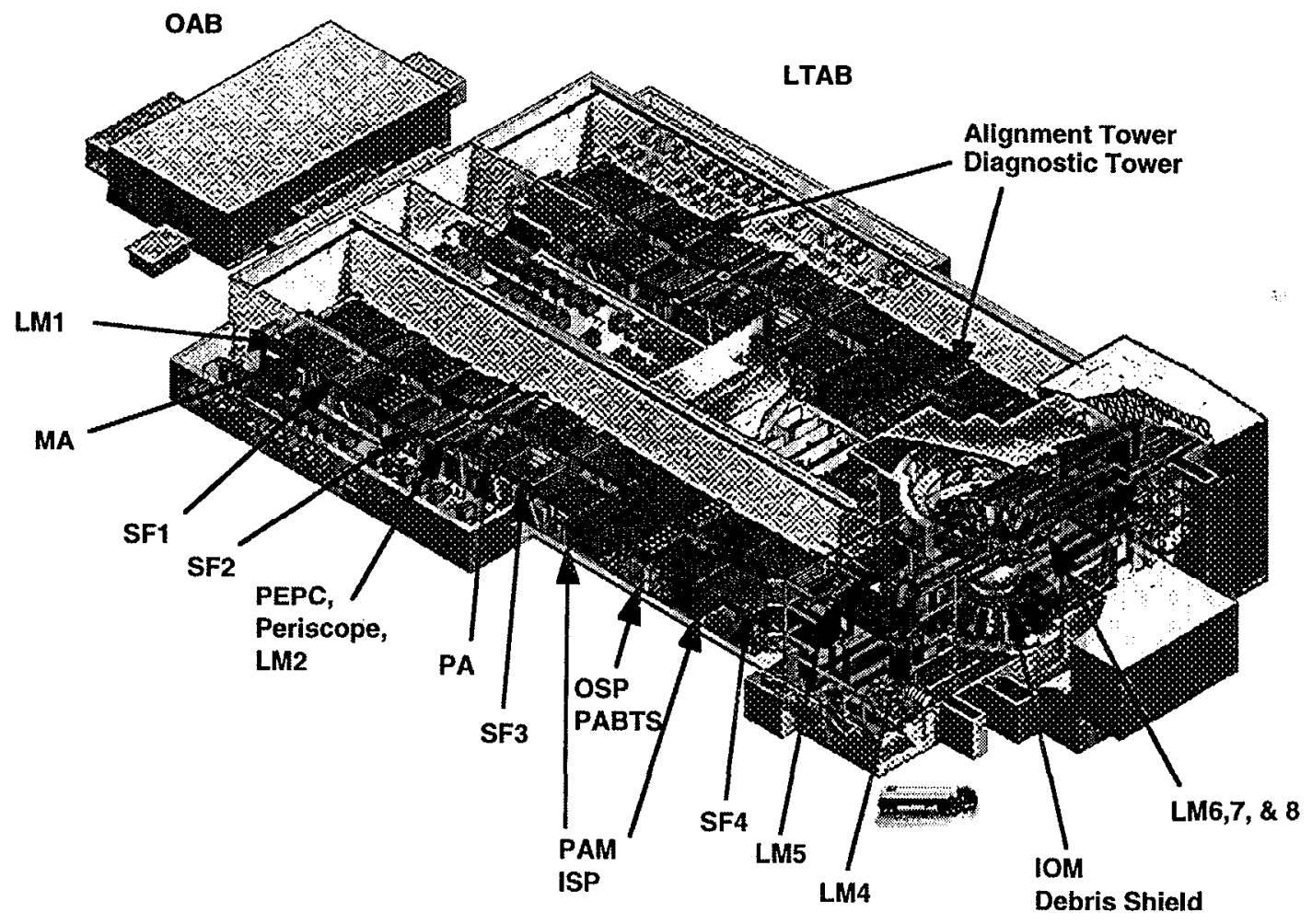

Figure 8. The LRUs are assembled and aligned in the OAB and then installed throughout the ITAB. 
The functions of the delivery systems are specified in a three-step process: "Get the LRU there," "Get the LRU close," and "Get the LRU in." Some of the delivery systems perform all three functions while others perform just the "Get it there" function.

Cleanliness is a key requirement for the delivery systems. Several measures are being implemented to ensure cleanliness. These include using cleanroom compatible components for the ballscrews and other linear actuators, using materials and greases approved by the NIF Contamination Control Group, and incorporating design concepts such as sandwiching two dirty surfaces together to trap particles and preserve cleanliness. The Bottom Loading and Top Loading Delivery Systems will also incorporate a HEPA airflow system inside the canisters, creating a mini cleanroom environment. The hardware will be tested to verify cleanliness requirements have been met.

\subsection{Transporter}

The delivery systems used in the Laser Bays (Bottom Loader, Top Loader, and Side Loader) share a common transporter that supports the "get it there" and the "get it close" functions. This transporter is a commercially provided Automated Guided Vehicle (AGV). An AGV transporter design was chosen for several reasons including the tight clearances required to maneuver. The parking tolerance for the transporter is \pm 0.5 inches, which can easily be accomplished more quickly with an AGV than with a manually driven forklift. Also, there are fewer personnel requirements with an AGV than with a conventional forklift-type vehicle. This could result in significant savings over the 30 -year life of NIF. The AGV uses a laser head and retroreflectors for its guidance system. The AGV can move autonomously. An example of an AGV is shown in Figure 9.

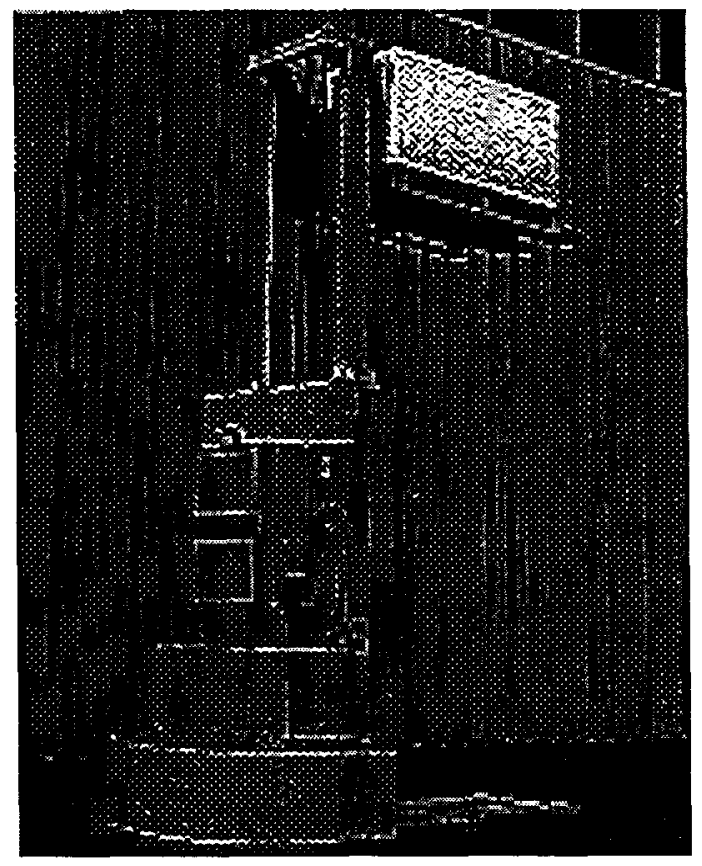

Figure 9. An AGV will move the Laser Bay LRUs to the specified locations.2

\subsection{Bottom Loading Delivery Systems}

The Bottom Loading Delivery System philosophy is to keep as much of the system designs for the 18 different optical LRUs in common as is possible. The design study resulted in three canister designs: an Amplifier-Slab configuration for installing the slab cassettes, a Flashlamp configuration for installing the flashlanp cassettes, and a "universal" configuration for installing all of the other bottom-loaded LRUs. There are over 2,700 individual bottom-loaded LRUs. Each type of LRU has 
unique design constraints including size, weight, insertion travel, kinematic mounts, utility conncctions, and beamline gas environment.

All three canister designs incorporate features to prevent the optics from becoming contaminated. These features include using low-outgassing greases, clean-room-compatible mechanisms, labyrinths enclosing mechanisms, and a HEPA filter airflow system to be used when the mechanisms are activated. The major subsystems on the canisters are the insertion mechanism, shelf mechanism, cover-removal mechanism, and spacer mechanism. See Figure 10. The AGV transporter will move all three canisters.
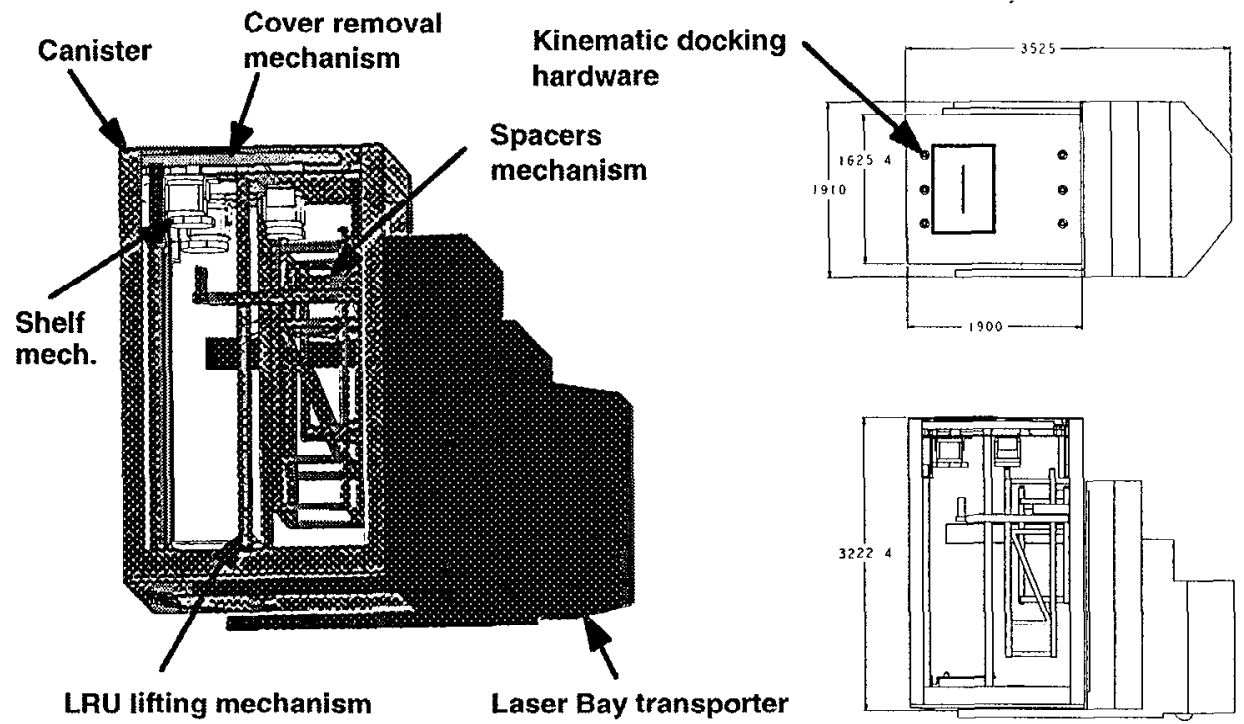

Figure 10. The universal canister is composed of several subsystems.

The Bottom Loading Delivery Systems will transport, lift, dock, and align the LRUs for installation in and removal from the Laser Bay beamlines. There are three different types of installation processes: single-stage, two-axis, and multi-stage installation. See Figures 11 to 13. The process for a single-stage installation is described below.

The delivery system is transported to the basement of the Optics Assembly Building (OAB). After docking to the floor of the OAB, a Class 100 clean LRU is inserted into the canister. The canister is then moved by the AGV to the LRU's insertion location under the laser beam structure. The AGV then lifts the canister to within an inch of the structure. The canister compliance system activates and completes the docking to the structure by having its kinematic docking balls self-align to the receivers in the structure. The compliance system allows the canister 6 degrees of freedom to the transporter. The canister's pneuma seal (inflatable seal) is activated, sealing the canister to the structure. The HEPA airflow system is activated. The cover-removal mechanism is activated, removing both the canister cover and the beamline cover together. The vertical ballscrew insertion mechanism then lifts the LRU to a height in the beam structure where the LRU's kinematic mounts are activated. The insertion mechanism then lowers the LRU onto the kinematic mounts. The insertion mechanism continues to lower the now empty carriage back into the canister. The cover-removal mechanism installs the covers back in place. The pneuma seal is deflated, and the transporter moves the empty canister back to the OAB. 


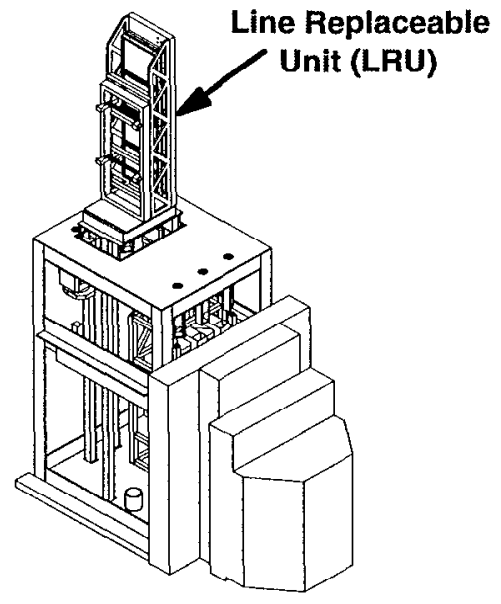

Figure 11. Single-stage lift.

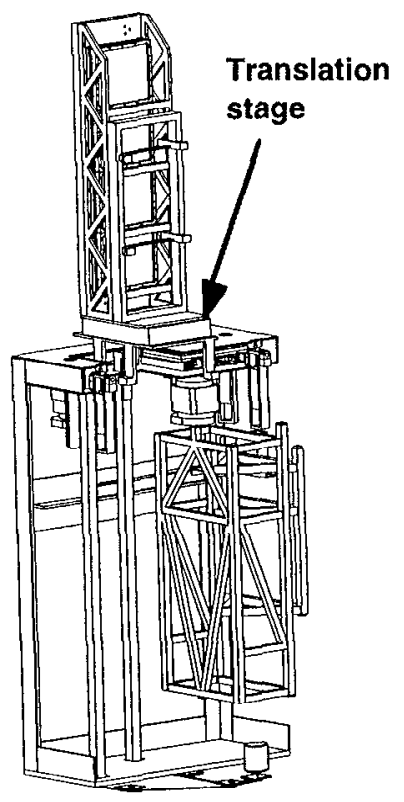

Figure 12. Two-axis insertion.

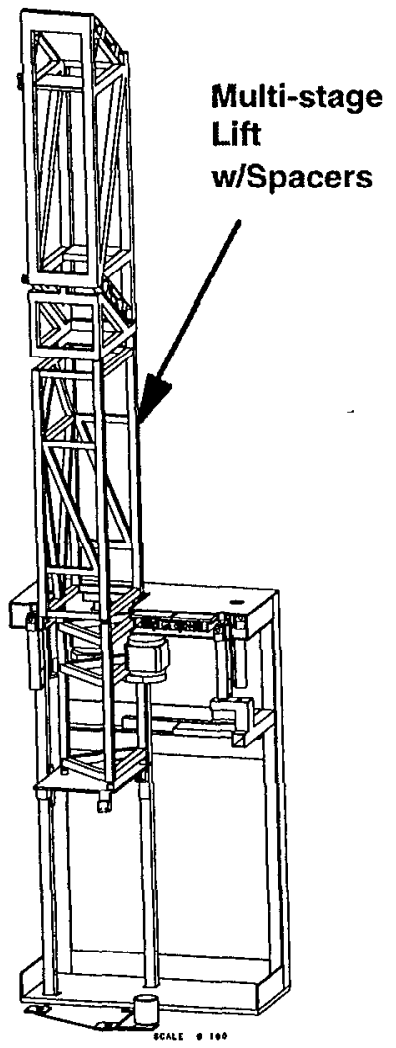

Figure 13. Multi-stage lift.

\subsection{Top Loading Delivery System}

The Top-Loading Delivery System will use a clean canister for transporting and inserting the three different top-loading LRUs. The LRU sizes have been standardized to simplify the delivery system design. This delivery system is maximizing design commonality with the Bottom Loading Delivery System to increase reliability and minimize cost. These LRUs are top loaded due to space limitations below the beamline structures.

To maintain cleanliness, the top-loading canister also uses clean-room-compatible materials and mechanisms, and a HEPA airflow system. The clean insertion of LRUs will be accomplished by using a cover-removal system similar to the bottomloading system in which the dirty outer surfaces of the vacuum and canister covers are sandwiched together and removed as a unit. The major subsystems on the canister are the insertion mechanism and the cover-removal mechanism. See Figure 14. The process for an installation is described below.

The delivery system is transported to the loft of the OAB. An LRU is inserted into the canister. The AGV moves the canister to the Laser Bay, where the Laser Bay bridge crane lifts the canister off the AGV. The crane docks the canister to the center vessels of the Cavity or Transport Spatial Filter. This process also seals the canister to the center vessel. The cover-removal mechanism activates and removes both the beamline and canister covers. The LRU is lowered onto the kinematic mounts at the bottom of the vacuum vessel by the ballscrew insertion mechanism. The insertion mechanism then moves the now empty carriage back inside the canister. The covers are replaced and the canister is undocked by the bridge crane. The crane places the empty canister onto the AGV for transport back to the OAB. 

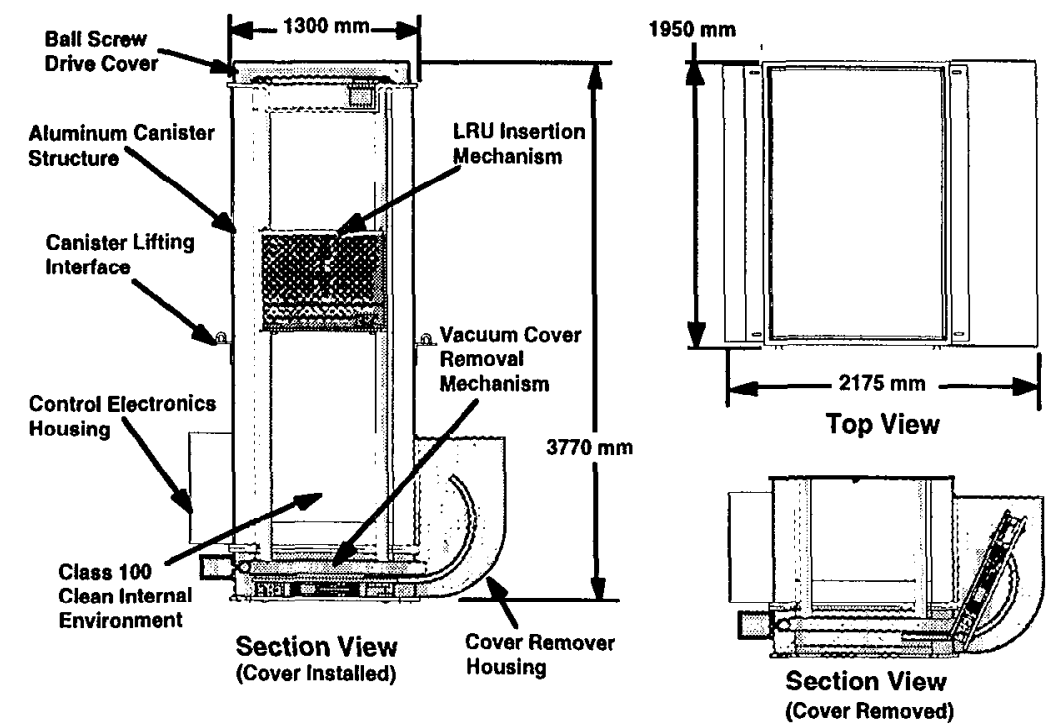

Figure 14. The Top Loading Delivery System transports and installs the Tower LRUs inside the Cavity Spatial Filter and Transport Spatial Filter center vacuum vessels.

\subsection{Side Loading Delivery System}

The Side Loading Delivery System comprises two separate delivery systems. The "PAM Delivery System" transports the preamplifier module (PAM) and Input Sensor LRUs. The "Output Sensor Delivery System" transports the Output Sensor LRUs.

The PAM Delivery System uses a skid to transfer the PAM and Input Sensor LRUs into the support structure. A batteryoperated tug moves the skid (which rolls on wheels) to transport the LRUs from the PAM maintenance area to the Laser Bay. In the Laser Bay, the skid is picked up by the Laser-Bay Transporter, which then positions and aligns the skid for docking. See Figure 15. There is a docking mechanism on the skid, which engages pins into receptacles in the support structure for alignment and support. Fine alignment of the skid to the support structure (in pitch and yaw) is done by using the vertical lift of the transporter (pitch) and an alignment actuator on the skid (yaw). The PAM and Input Sensor LRUs have wheels, on which they roll from the skid into the support structure. A rack and pinion mechanism on the skid inserts the LRUs into (and retracts them from) the support structure. The LRU is connected to the drive mechanism by a rotary latch. The skid is then removed and returned to its original point of origin.

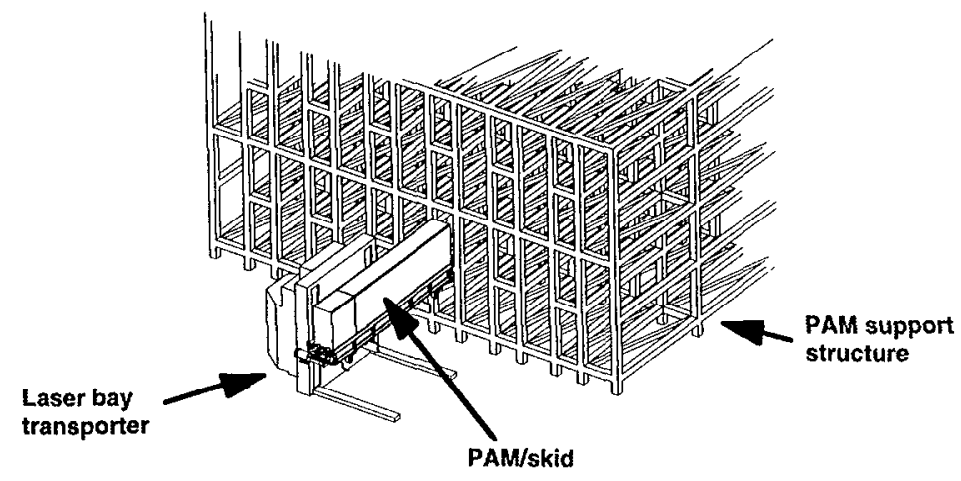

Figure 15. The Side Loading skid is docked to the structure for the PAM installation. 
The Output Sensor Delivery System uses a modified manual lift truck for transporting and installing the LRUs. Customdesigned lifting forks interface with the Output Sensor. Due to tight clearances, the legs of the Output Sensor Transporter must travel under the support structure and the lifting forks must hinge up during the installation and removal of LRUs. See Figure 16.

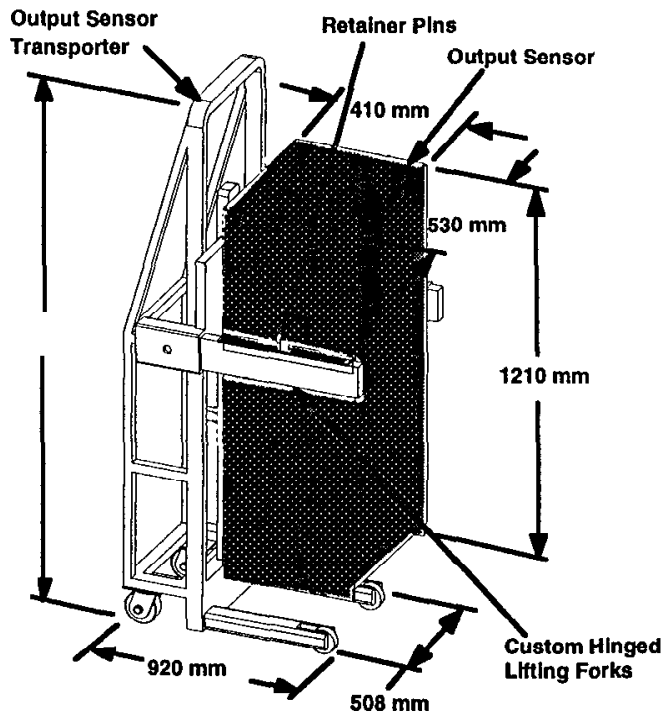

Figure 16. The Output Sensor Package is installed with a manual transporter.

\subsection{Switchyard Delivery System}

The Switchyard Delivery System design philosophy is based on modularity and commonality. There are seven separate optic configurations requiring handling in the switchyard. Several of these optics are enclosed, so their cleanliness can be ensured by transportation without support equipment. However, there are a few "bare" optics (for the Precision Diagnostic and the Roving Mirror Systems) requiring an enclosure to protect them from the dirty outside environment. The switchyard LRUs are transferred to the delivery systems from the airlock of the OAB.

Although the Switchyard mirror optics are unique, the delivery systems are the same: a skid/carriage and a cradle support the LRU while they are being transported to the Switchyard. See Figure 17. Once the LRU is transported to the specified floor level, a monorail system lifts the LRU with its cradle and carriage off the transporter and skid. The monorail transits the LRU within the Switchyard structure to the desired docking location. The carriage docks to the permanent rail system and the LRU is transferred to the rail system for final installation.

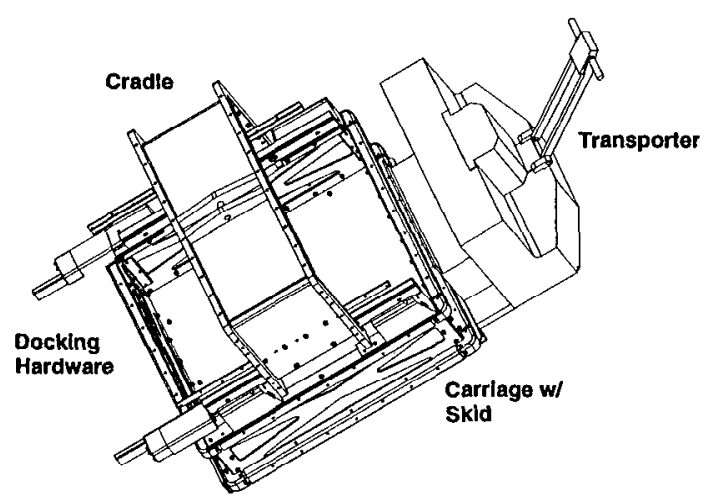

Figure 17. The delivery system for the Switchyard mirrors is designed to dock to the mirrors' permanent rails for final installation. 
The enclosures required for handling the bare LRUs are unique, but the same skid and transporter are usable for these LRUs. These enclosures dock to the LRU structures for installation/removal operations.

\subsection{Target Area Delivery System}

The Target Area Delivery System is the most elementary of all delivery systems. The delivery system functions only as an LRU carrier/transporter. This system transfers the LRUs from the airlock of the OAB to the specified floor level in the Target Building. Once on the specified floor level, the LRU is handed off to the optics delivery system in the target area for final installation.

The Target Area Delivery System design philosophy is a "carbon copy" of that used for the switchyard system design, with as much modularity and commonality as possible. In fact, the Switchyard Delivery System and the Target Area Delivery Systems are very similar, using the same type of transporter and skid concept. An additional lifting feature may be incorporated, which may assist with transfers from the Optical Transport and Material Handling System to the opticsdelivery system.

\subsection{SUMMARY}

The Optical Transport and Material Handling Delivery Systems are being designed to meet the NIF requirement of rapid installations/removals of the LRUs. The systems will accommodate the numerous constraints from the Optics Assembly Building and the Laser and Target Area Building facilities, the laser support structures, the laser beam enclosures, and the various LRUs. Commonality is being maximized for all the systems. During 1998, the Bottom Loading, Top Loading, Side Loading, and Switchyard Delivery Systems will begin testing for proof of principles and cleanliness verification. The testing will validate the design concepts and will lead to production of the various delivery systems for the NIF project. Completion of final delivery system designs are anticipated in early calendar year 1999.

\subsection{ACKNOWLEDGMENTS}

The work noted in this paper was prepared through the support of the Optical Transport and Material Handling Design Group within the NIF Operations Engineering Section. This dedicated team includes Mike McDaniel, Mike Weddle, Kelly Holm, Dannie Johnson, John Stencil, Don Coufal, Gerry Kehl, Tom Kelly, Ray Iaea, Sudhir Jain, Kent Lueng, Steve Lu, Jo Sander, Mark Perez, Dennis Silva, Donn McMahon, Brett Hall, Rudy Carpenter, Bill Spruit, Milt Martini, Jon Marks, Stan Trettenero, Jeff Olsen, Ladonna Willis, Leslie Allision, Ken Montgomery, Tamra Porter, and Sandra Owens.

This work is performed under the auspices of the U. S. Department of Energy by Lawrence Livermore National Laboratory under Contract W-7405-ENG-48.

\subsection{REFERENCES}

1. National Ignition Facility Conceptual Design Report, Volume 2: "Design Basis and Requirements," UCRL-PROP117093, Vol. 2, Lawrenece Livermore National Lahoratory, Livermore, CA 94550.

2. Automated Guide Vehicle Systems and Components, AGV Products, Inc., 8000 Tower Point Drive, Charlotte, North Carolina, 28227. 


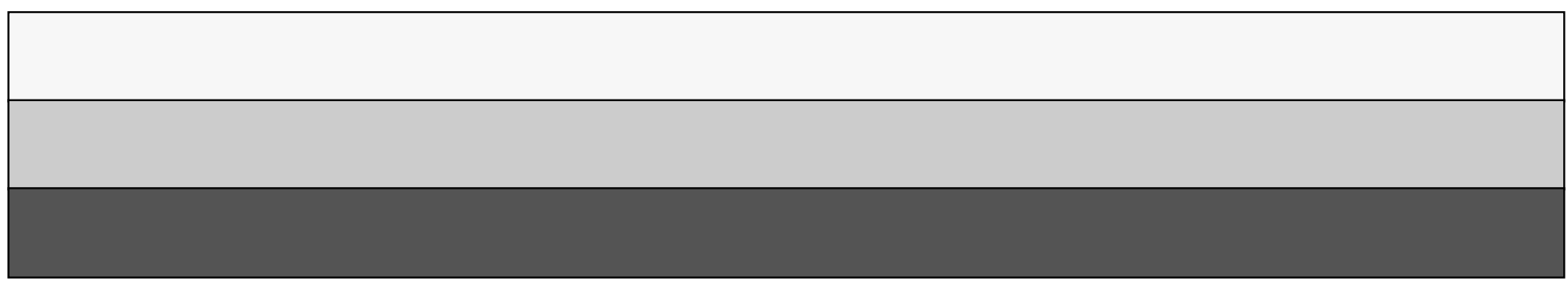

